\title{
The prevalence of smoking in male medical students from 16 Chinese medical colleges and the associated factors
}

\author{
Xiaohong Yang ${ }^{1,2 \#}$, Weizhong Chen ${ }^{2 \#}$, Xiaoli Peng ${ }^{2}$, Changyou Wei ${ }^{2}$, Junguo Xin ${ }^{2}$, Jiayang Tang ${ }^{2}$, \\ Jian Chen ${ }^{2}$, Ziqian Zeng ${ }^{2}$, Rongsheng Luan ${ }^{1}$ \\ ${ }^{1}$ West China School of Public Health, Sichuan University, Chengdu, China; ${ }^{2}$ School of Public Health, Chengdu Medical College, Chengdu, China \\ Contributions: (I) Conception and design: X Yang, W Chen, R Luan; (II) Administrative support: R Luan, C Wei, J Chen; (III) Provision of study \\ materials: X Yang, W Chen, X Peng, J Xin, J Tang, Z Zeng; (IV) Collection and assembly of data: X Yang, W Chen, X Peng, J Tang; (V) Data \\ analysis and interpretation: X Yang, W Chen; (VI) Manuscript writing: All authors; (VII) Final approval of manuscript: All authors. \\ "These authors contributed equally to this work as co-first authors. \\ Correspondence to: Rongsheng Luan. West China School of Public Health, Sichuan University, 16\#, Section 3, Renmin Nan Lu, Chengdu, 610041, \\ China. Email: luan_rs@scu.edu.cn.
}

\begin{abstract}
Background: The prevalence of smoking among Chinese medical students in medical colleges is a matter of significant concern. This study aimed to explore the prevalence of smoking and the associated factors among these students.

Methods: A total of 7,728 students from 16 colleges in 12 provinces were surveyed to measure their smoking behaviors, attitudes toward tobacco control, and knowledge about smoking risk. An evaluation of campus environment and policy was conducted at the same time. Frequencies were calculated using weighted estimators for complex sampling. A two-level logistic regression model was used to assess factors associated with current smoking.

Results: The prevalence of smoking among male medical students in the 16 medical colleges was $12.8 \%$. Students' participation in smoking, smoking initiation after school enrollment, and intention-to-quitsmoking rates may be influenced by their anti-tobacco attitude, the belief that smoking can help to relieve stress, their parents' smoking behaviors, their best friend's attitude towards smoking and second-hand smoke exposure (SHSE), and their awareness of tobacco hazards.

Conclusions: This study provides sufficient evidence to support the implementation of systematic intervention strategies to decrease the smoking rate among male medical students. These strategies may include tobacco control education, smoking cessation technologies, communication, and the enforcement of smoke-free policies to create a tobacco-controlled campus environment.
\end{abstract}

Keywords: Smoking behavior; Chinese male medical students; influence factors

Submitted Sep 14, 2020. Accepted for publication Nov 14, 2020.

doi: 10.21037/apm-20-2101

View this article at: http://dx.doi.org/10.21037/apm-20-2101

\section{Introduction}

The prevalence of smoking in China has remained alarmingly high since 1996, and smoking is the single most important preventable risk factor for mortality in China. The Global Adult Tobacco Survey (GATS, 2018) (1) reported the smoking rate among Chinese males aged $\geq 15$ years to be $50.5 \%$. In $2018,50.9 \%$ of non-smoking adults in China were subjected to second-hand smoke exposure (SHSE) in the workplace, and $44.9 \%$ of them were exposed to tobacco smoke at home (1). Smoking is one of the main causes of male death in Asia. In China, the ratio of male ever-smokers continues to increase: among men born in or after 1950, $79.4 \%$ of those living in urban areas and $74.3 \%$ of those living in rural areas have smoked at some point in their lives (2). Parascandola and Xiao (3) found that 
smoking-related health issues in China have increased over the past two decades, and the prevalence of smoking among Chinese men has remained high, standing at approximately $60 \%$ in the 1980 s with a modest decrease to $52 \%$ by 2015 . In 2013, the number of deaths attributable to smoking in China reached 1.59 million, accounting for $17.38 \%$ of total deaths (4). To curb tobacco use and its associated mortality and morbidity, the Chinese government ratified the World Health Organization Framework Convention on Tobacco Control (WHO FCTC) in 2005 and has introduced a series of tobacco control interventions. However, many studies have shown that few of these efforts have been successful (5), and there is still a large gap between tobacco control in China and the requirements of the FCTC $(6,7)$.

Experience in some developed countries, such as the United States and the United Kingdom, shows that medical professionals can play an important role in tobacco control by serving as role models for healthy, non-smoking behaviors, promoting anti-smoking to be the social norm, and advising patients on quitting smoking $(8,9)$. Notably, the smoking rate among doctors is always lower than that of the general population $(10,11)$. Because doctors have a highly respected professional and social status, their words and behaviors have a substantial influence on ordinary people, especially their patients. In fact, research has shown that advice from medical doctors can effectively help patients to make decisions and take actions to quit smoking (12-14).

Thus, medical professionals, especially medical students, have the greatest potential of any group in society to play a key role in tobacco control in China. Successful tobacco control interventions and education among medical students can improve their knowledge and awareness about tobacco use, equip them with the clinical skills needed to control tobacco use, mobilize them to assume social leadership in the efforts against tobacco use, and help to lower the smoking rate among future medical doctors and the general population.

Although many studies have described the smoking behaviors of Chinese students (15-17), little research has been conducted among Chinese medical students specifically. The studies that have been carried out (18-20) were limited and mostly based on small and unrepresentative samples obtained, often from a single city or area. Moreover, they did not analyze or provide detailed information such as smoking intensity, smoking prevalence among student subgroups, or the status of smoking initiation and cessation, and the related factors.
The present study aimed to fill this knowledge gap by studying the smoking behaviors of Chinese medical students at 16 medical universities in 12 provinces in China. The surveyed regions and sample size were carefully considered to ensure more precise and representative estimations of smoking behavior rates. Specifically, our study aimed to explore the key factors influencing current smoking participation, smoking initiation after school enrollment, and intention to quit smoking among medical students. To identify students who initiated smoking after entering medical school, the respondents were asked about their grades and the time of their first cigarette. The findings of this study will provide evidence for medical colleges to devise effective interventions for tobacco control among medical students.

We present the following article in accordance with the SURGE reporting checklist (available at http://dx.doi. org/10.21037/apm-20-2101).

\section{Methods}

\section{Study sites and data collection}

As shown in Figure 1, our study was conducted in 16 medical colleges in 12 provinces throughout China in 2018. These medical colleges aimed to create non-smoking medical campuses and develop medical leadership in tobacco control in China. The study comprised a questionnaire survey of medical students, campus environmental observation, and an evaluation of anti-tobacco policy at the participating schools.

The survey questionnaire was developed based on expert discussion and the standard WHO tobacco survey questionnaire. Stratified cluster sampling was used to ensure these samples were representative for the population. The primary sampling unit was class, with 605 students at each college selected to be surveyed. The questionnaire survey was conducted on the medical campuses. Because in some comprehensive universities, first-year medical students often live on the main campus rather than the medical campus, and fourth- and fifth-year students undertake professional internships off campus, only second- and third-year undergraduate medical students were interviewed. Given that the smoking rate of female students in China is usually lower than that of male students $(21,22)$, only male medical students were enrolled. Of 7,728 questionnaires distributed, 7,294 were collected, with a return rate of $94.4 \%$; among the 7,294 returned questionnaires, 7,169 (98.3\%) were valid. 


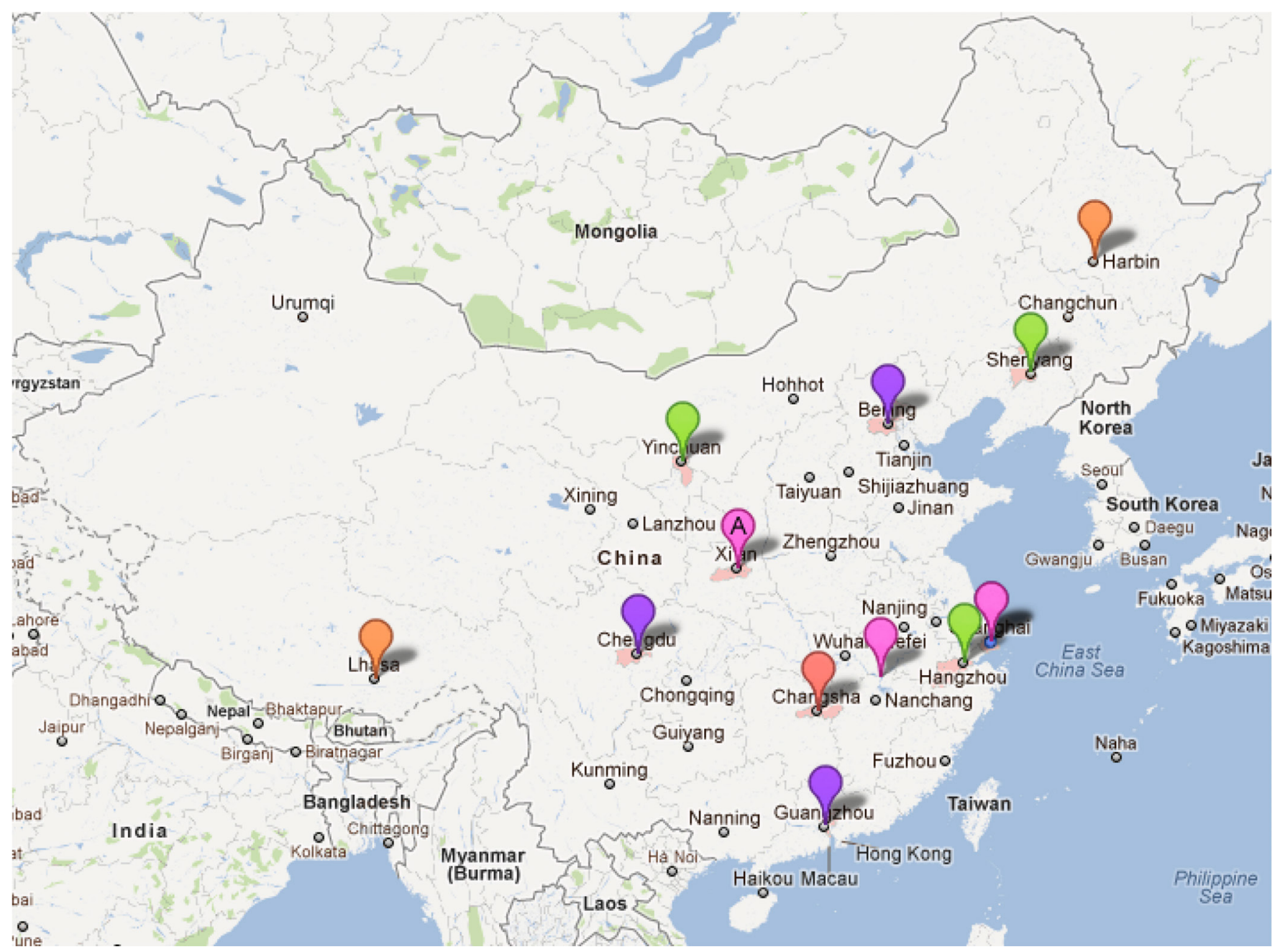

Figure 1 Geographical distribution of our survey. Our study involved 16 medical colleges from 12 representative provinces throughout China.

The environmental observation included observing and recording the number of smokers, cigarette butts, and anti-tobacco signs at different sites on campus. This information was used to assess college-level SHSE. The policy evaluation involved checking and anti-tobacco policy and regulation documents at the schools. This information was used to define the existence of an anti-tobacco policy at a college and to determine the length of its implementation.

All procedures performed in this study involving human participants were in accordance with the Declaration of Helsinki (as revised in 2013). The study was approved by institutional ethics committee of Sichuan University (No.: 20180412, the registration number of ethics committee) and informed consent was taken from all the participants.

\section{Data collection}

\section{Smoking status classification}

A current smoker is defined as a person who has smoked during the past 30 days. Smoking initiation after school enrollment referred to the first cigarette smoked by an individual after entering college. Intention to quit was judged based on the survey subject's response to the question "Are you planning to quit smoking?".

\section{Individual-level tobacco control variable}

Factors which influence smoking behaviors include demographic characteristics (e.g., age, gender, race/ ethnicity), knowledge, beliefs and attitude towards smoking, and the influence of peers and parents (e.g., their smoking 
behaviors and attitudes towards smoking). In addition to the individual level variables listed above, macro-level factors such as anti-tobacco policy, laws, and regulations can also influence smoking behavior.

\section{Knowledge of smoking-related health issues}

Respondents were asked whether they believed that smoking can cause serious diseases such as stroke, heart disease, lung cancer, and that second-hand smoke (SHS) can cause serious diseases including adult lung cancer, adult heart diseases, and pediatric lung diseases among non-smokers.

\section{Anti-tobacco attitudes}

The respondents were asked whether they agreed that medical students should reject smoking, be anti-tobacco role models, and work to persuade the public to quit smoking. The responses were scored as $0=$ 'no' or $1=$ 'yes'. The variable attitude was created by calculating the number of times the respondents answered 'yes' (range $=0-3$ ).

\section{Benefits associated with smoking}

The respondents were asked whether they believed smoking can bring joy, relieve stress, improve concentration, help with social communication, and help them to express their personality. The responses were scored as $0=$ 'no' or $1=$ 'yes'.

\section{Smoking behaviors and attitudes of students' parents and best friends}

The respondents were asked about whether their parent smoke. The possible responses were 'none', 'only father', 'only mother', or 'both'. The respondents were also asked "Does your best friend agree with smoking or not?". The possible responses were 'They completely disagree', 'they disagree a little', 'they have no opinion', or 'they agree'.

\section{School-level tobacco control variable}

Time of college's anti-tobacco policy execution

Details of when anti-tobacco policy was first introduced in the participating colleges were collected in the policy evaluation.

\section{Anti-smoking signs}

Based on the observational results, the variable signs was created to assess the density of anti-smoking signs on campus, which was calculated according to the proportion of school facilities with anti-tobacco signs divided the total number of school facilities investigated.

Tobacco advertisements

The respondents were asked whether they had seen any tobacco advertisements or promotions on campus in the past month. The corresponding variable created was advertisements, and the responses were scored as $0=$ 'no' or 1 = 'yes'.

\section{College classification}

The binary variable top college was created to indicate whether a college was a top college directly under the Ministry of Education.

\section{SHSE}

SHSE and students' smoking behaviors are closely interlinked, and higher SHSE may lead to more smoking. In particular, college-level SHSE can reflect the enforcement status of schools' anti-tobacco policies, and individual-level SHSE can reflect the smoking environment on campus, which can directly influence the smoking behaviors of students. Therefore, both college-level and individual-level SHSE were included as independent variables in this study.

The variable college_SHSE was created to reflect the first component calculated by the principal component analysis on the following variables: the medians of cigarette butts found in teaching buildings, administrative buildings, and male dormitories, respectively; the proportion of school facilities where cigarette butts were found; and the proportion of school facilities where smokers were observed.

The variable individual_SHSE was created to record the first component calculated by the principal component analysis on variables used to assess individual level SHSE. The respondents were asked whether they had seen other people smoking in the following places during the past 30 days: dormitory rooms, teaching buildings, administrative buildings, the school cafeteria, school buses, and campus stores. The responses were scored as 0 = 'no' or 1 = 'yes'. The variable SHSE score was created by calculating the number of 'yes' responses (range $=0-6$ ). The respondents were also asked 'How often have you seen other people smoking on campus or in the classroom during the past week?' The possible responses were ' 0 days', ' 1 2 days', '3-4 days', '5-6 days', or 'every day'. The SHSE scores were used to assess individual-level SHSE.

\section{Others}

The binary variable access was created to capture the response to the question: 'Is it easy or difficult for you to get a cigarette when you want to smoke?' The categorical variable quantity was created to reflect the answer to the question 'How many cigarettes have you smoked on average each day during the past 30 days?' The possible responses were '<1 cigarette', ' 1 cigarette', ' $2-5$ cigarettes', '610 cigarettes', '10-20 cigarettes', or '>20 cigarettes'. The 
Table 1 The current smoking rate, smoking initiation rate, and intention-to-quit rate among current smokers according to different demographic characteristics

\begin{tabular}{lccccc}
\hline Variable & Subgroup & $\mathrm{n}$ & Current smoking rate (\%) & Smoking initiation rate (\%) & Intention-to-quit rate (\%) \\
\hline Grade & Sophomore & 3,720 & 12.4 & 53.3 & 63.0 \\
Ethnic group & Junior & 3,239 & 12.7 & 54.0 & 61.1 \\
& Han & 6,441 & 11.2 & 52.2 & 59.9 \\
& Hui & 196 & 28.2 & 66.7 & 71.5 \\
& Tibetan & 101 & 44.4 & 83.9 & 75.2 \\
Major & Other & 422 & 17.9 & 56.9 & 71.0 \\
& Clinical & 3,919 & 12.3 & 52.8 & 63.8 \\
& Public Health & 512 & 18.5 & 60.7 & 66.7 \\
& Basic Medical & 910 & 13.1 & 52.2 & 55.3 \\
& Nursing Science & 87 & 19.3 & 58.8 & 68.3 \\
& Pharmacy & 918 & 13.1 & 56.1 & 59.7 \\
& Dentistry & 264 & 6.6 & 47.4 & 60.9 \\
Region & Other & 527 & 8.8 & 47.9 & 49.1 \\
& Eastern & 2,309 & 5.2 & 43.6 & 42.4 \\
& Central south & 1,150 & 13.9 & 58.8 & 67.2 \\
& Northeastern & 1,186 & 10.5 & 47.3 & 55.9 \\
& Western & 2,524 & 19.7 & 62.7 & 67.7 \\
\hline
\end{tabular}

categorical variable fee was created to reflect the answer to 'How much have you spent on cigarettes during the past 30 days?'. The possible responses were '<50 Yuan', '51100 Yuan', '101-300 Yuan', '301-500 Yuan', or ‘>500 Yuan'. The binary variable stopped was created to reflect the answer to 'During the past 30 days, have others stopped you when you were smoking?'. Finally, the binary variable advice was created to reflect the answer to 'Have you been advised to quit smoking during the past 12 months?'. Since only smokers were asked the questions above, the corresponding variables were only used in the analysis of factors that influence students' intention to quit.

\section{Statistical analysis}

A multivariate analysis incorporating the above variables was carried out to assess students' survey responses. Since the dependent variables of the three questions above are binary and a two-level structure (college-individual) of data existed, a two-level logistic regression model was used in the analysis.
Statistical analyses were carried out using SAS software (version 9.4 for Windows, SAS Institute, Inc., Cary, NC, USA). The inspection level $\alpha$ is set to 0.05 unless otherwise specified. The current smoking status of male medical students was first described with weighted summary statistics. Then, the factors influencing students' smoking behaviors (participation, initiation, and intention to quit) were determined using two-level logistic regression models.

\section{Results}

\section{Characteristics of questionnaire data}

The 7135 medical students in our study had a mean age of 21.2 years old, and $90.0 \%$ of the participants were Han. Demographic characteristics of the students surveyed are shown in Table 1.

\section{Smoking patterns of medical students}

Of all male medical students surveyed in this study, $12.4 \%$ 
were self-reported current smokers, among whom 30.7\% initiated smoking after college enrollment and $25.9 \%$ claimed to smoke daily. In the preceding 12 months, $22.4 \%$ of ever-smokers had attempted to quit, but only $4.8 \%$ had been successful. Of the current smokers, $62.2 \%$ indicated an intention to quit. Table 1 shows the rates of current smoking, smoking initiation, and intention to quit among current smokers according to different demographic characteristics.

\section{Multi-level analysis}

\section{Analysis of current smoking rates}

The current smoking rate was analyzed using a two-level logistic model, and the results are presented in Table 2.

As shown in Table 2, ethnic group and region were significantly correlated with current smoking rates. The smoking rates of students from ethnic minorities, especially Hui and Tibetan students, were higher than that in the Han population ( $\mathrm{OR}=2.24$ and $\mathrm{OR}=2.84$, respectively). The smoking rate among students in medical colleges in central and western China was higher than that of students in colleges in eastern China $(\mathrm{OR}=1.75$ and $\mathrm{OR}=1.80$, respectively). Such regional differences may be caused by the imbalanced development between eastern and western China.

Beliefs and attitudes related to smoking were also found to be correlated with students' current smoking status. Students who held a positive anti-tobacco attitude were less likely to be current smokers $(\mathrm{OR}=0.69)$. The smoking rate among students who agreed that smoking can relieve pressure was higher than that of students who disagreed $(\mathrm{OR}=1.41)$. The smoking rate of students who agreed that smoking can help express their personality was lower than that of the students who disagreed $(\mathrm{OR}=0.67)$.

The smoking behavior of students' parents and the attitude of their best friend towards smoking were found to significantly affect students' current participation in smoking. Compared with students whose parents did not smoke, students who had a father or both parents who smoked were more likely be smokers ( $\mathrm{OR}=1.33$ and $\mathrm{OR}$ $=2.68$, respectively). Students whose best friends approved of smoking were also found to be more likely to be a current smoker $(\mathrm{OR}=1.57)$. Additionally, students who had higher individual-level SHSE were more likely to be current smokers $(\mathrm{OR}=1.47)$. This can be explained by the fact that a heavy smoking environment (strong SHSE) may lead to a high probability of smoking.

\section{Analysis of smoking initiation}

Smoking initiation (initiated smoking before or after school enrollment) was analyzed with a two-level logistic model with controlling for all related explanatory variables mentioned earlier. In this analysis, 5,339 students were nonsmokers before school enrollment, and 557 of them had started smoking after enrollment. These results are presented in Table 3.

As shown in Table 3, a student's attitude and beliefs towards smoking, their best friend's attitude towards smoking, whether their college was a top medical college or not, and the and individual level of SHSE were factors influencing smoking initiation. Specifically, students who held a positive anti-tobacco attitude were less likely to start smoking after entering college ( $\mathrm{OR}=0.858)$, while students who agree that smoking can relieve the pressure and that smoking is good for social communication were more likely to start smoking after enrollment ( $\mathrm{OR}=1,852$ and $\mathrm{OR}=1.567$, respectively). Students whose best friends approved of smoking were more likely to initiate smoking ( $\mathrm{OR}=1.754)$. Compared with students from non-top medical colleges, students in top colleges were less likely to start smoking after entering school ( $\mathrm{OR}=0.623$ ). The higher the college- and individual-level SHSE, the more likely a student was to initiate smoking (OR $=1.156$ and $\mathrm{OR}=1.255$, respectively).

\section{Analysis of intention to quit smoking}

This analysis builts models for the intention to quit smoking (intend to quit or not) among 910 current smokers using a two-level logistic model. Table 4 presents the results of the analysis. The factors influencing the student smokers' intention to quit included the student's own knowledge and attitude towards smoking, the attitude of their best friend towards smoking, and whether they had been advised to quit smoking or not. More specifically, the more a student knew about the health hazards of smoking, the more likely they were to intend to quit ( $\mathrm{OR}=2.843)$. Students who held a positive anti-tobacco attitude were also more likely to quit ( $\mathrm{OR}=1.636)$, as were students who had ever been advised to quit smoking $(\mathrm{OR}=6.153)$. However, students whose best friends approved of smoking were found to be less likely to quit $(\mathrm{OR}=0.612)$.

\section{Discussion}

The prevalence of smoking among male medical students in the 16 medical colleges that participated in this study was $12.8 \%$, which is much higher than that of male medical 
Table 2 Multilevel analysis of students' current smoking participation ( $\mathrm{n}=7,135)$

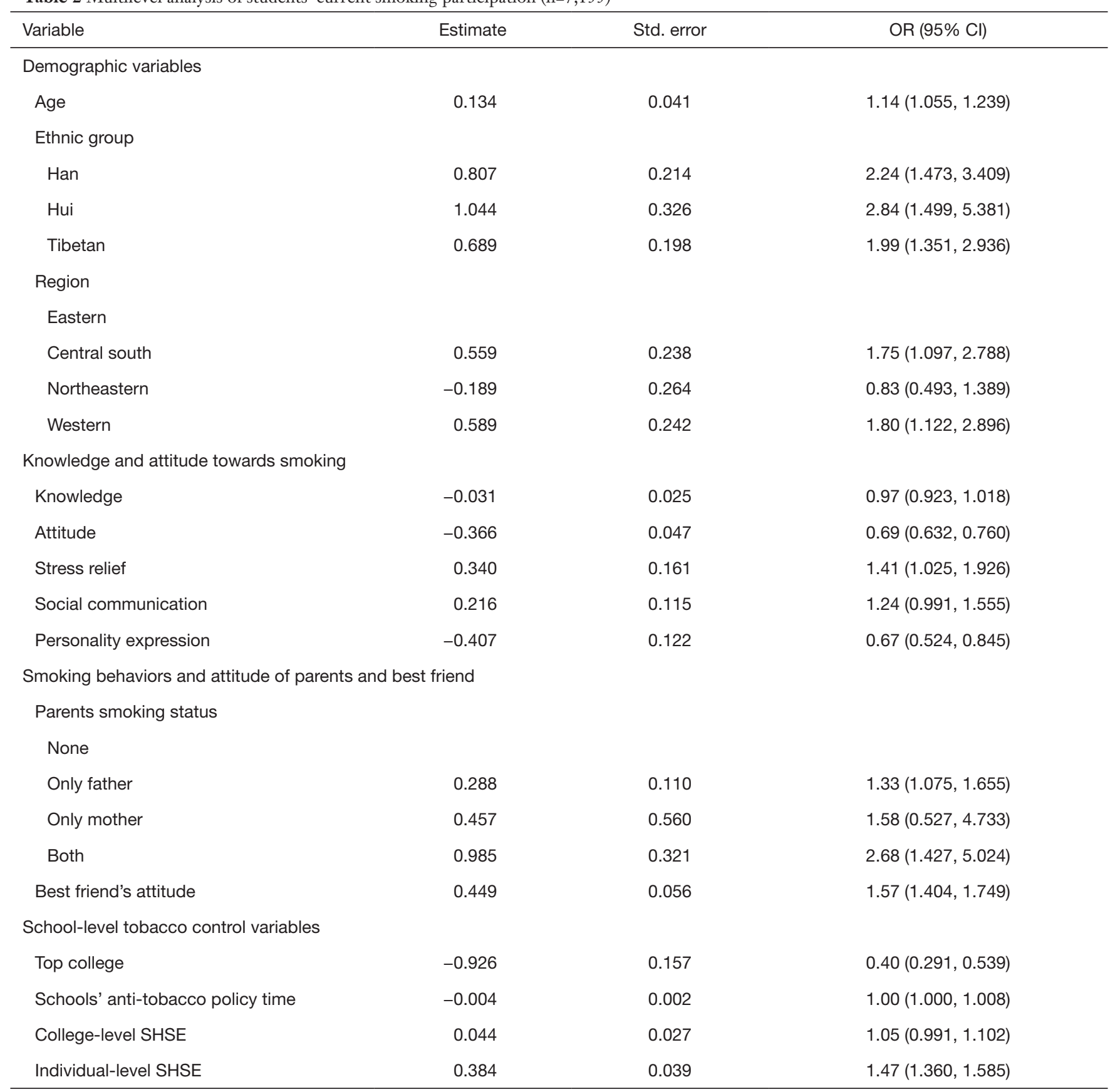

SHSE, second-hand smoke exposure.

students of the United States or the United Kingdom (2.2\%). Compared with that in other studies $(17,20,23,24)$, the smoking prevalence among students in our study was obviously lower. The differences between our results and those of previous research may partly be explained by sociocultural and geographic variations, as well as the year in which this study took place.

This study showed that about $70 \%$ Chinese male medical students smoked their first cigarette before entering the college, which was in accordance with the results of other national surveys (22). This suggested that proper antitobacco intervention should be carried out for students in 
Table 3 Multilevel analysis of students' smoking-initiation ( $\mathrm{n}=5,339)$

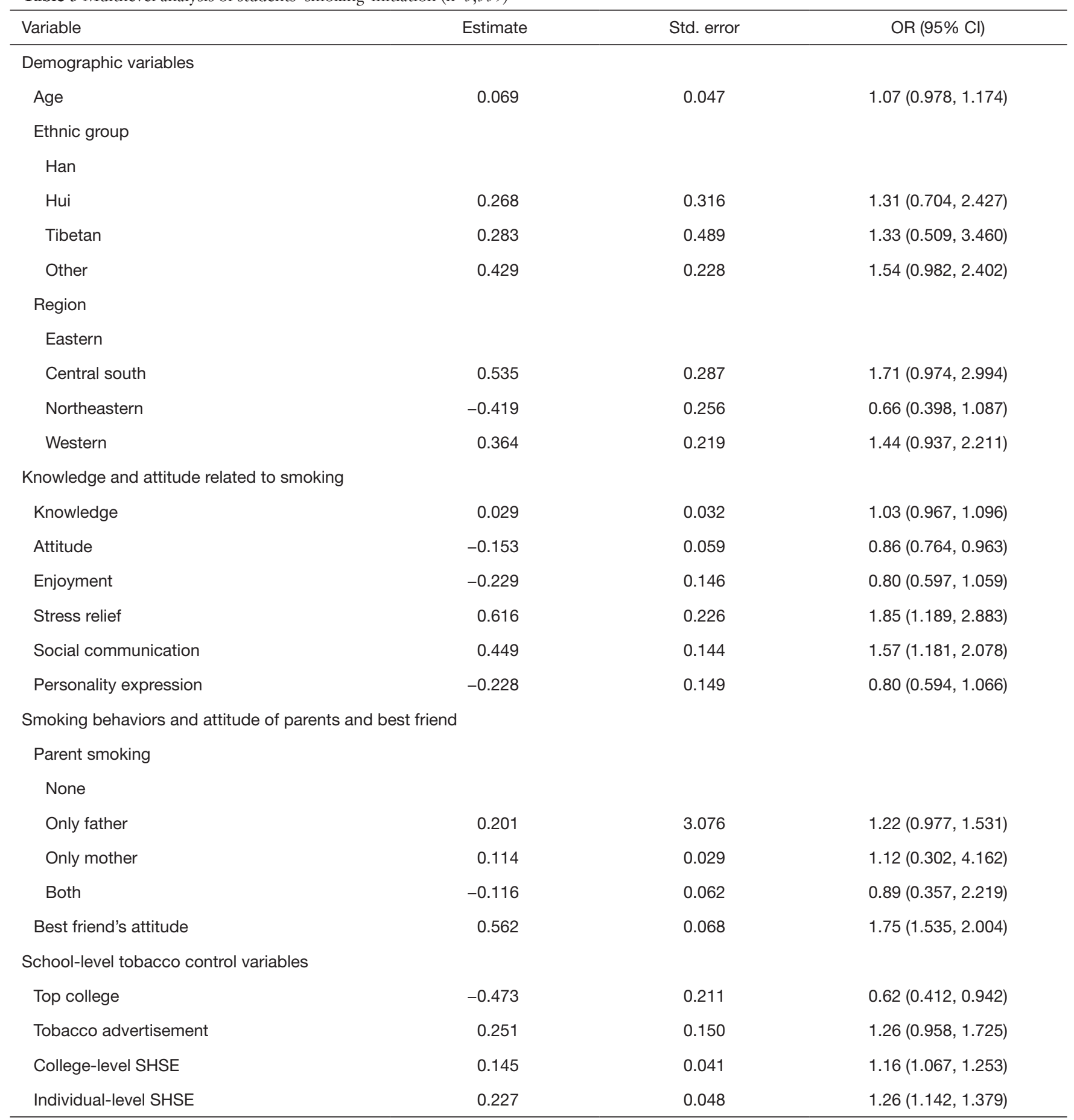

SHSE, second-hand smoke exposure.

middle-school or even in primary school to prevent smoking initiation. Still, $30 \%$ of students began smoking after college enrollment, which implied that effective measures need to be taken immediately after medical students enroll in college in order to reduce the possibility of initiation. Furthermore, some different health education contents may 
Table 4 Multilevel analysis of student smokers' intention to quit ( $\mathrm{n}=910)$

\begin{tabular}{|c|c|c|c|}
\hline Variable & Estimate & Std. error & OR $(95 \% \mathrm{Cl})$ \\
\hline Age & 0.215 & 0.109 & $1.240(1.001,1.535)$ \\
\hline \multicolumn{4}{|c|}{ Knowledge and attitude related to smoking } \\
\hline Knowledge & 1.045 & 0.444 & $2.843(1.191,6.789)$ \\
\hline Stress relief & 0.105 & 0.062 & $1.111(0.984,1.254)$ \\
\hline Social & 0.068 & 0.292 & $1.070(0.604,1.897)$ \\
\hline \multicolumn{4}{|c|}{ Smoking behaviors and attitude of parents and best friend } \\
\hline Best friend & -0.491 & 0.170 & $0.612(0.439,0.854)$ \\
\hline \multicolumn{4}{|c|}{ School-level tobacco control variables } \\
\hline Top college & -0.364 & 0.320 & $0.695(0.371,1.301)$ \\
\hline P time & 0.012 & 0.005 & $1.012(1.002,1.022)$ \\
\hline \multicolumn{4}{|l|}{ Random effect } \\
\hline Level 2 SE $\sigma_{u_{0}}^{2}$ & 0.248 & 0.149 & - \\
\hline Scale parameter $\delta$ & 0.997 & 0.076 & - \\
\hline
\end{tabular}

be provided to the different students.

This study found that male students' attitudes towards tobacco and the attitude of their best friend towards smoking influenced all three types of smoking behavior measures (participation, initiation, and intention to quit). Students who held a positive anti-tobacco attitude were less likely to be current smokers and to initiate smoking after entering university, and they were also more likely to intend to quit smoking. Moreover, students whose best friends approved of smoking were more likely to be current smokers and to initiate smoking after entering university; these students were also less likely to quit smoking.

Other factors have been found to influence either one or two types of smoking behavior. Generally speaking, a student's smoking behaviors, especially smoking participation, were significantly positively correlated with those of his parents. This link gradually weakened after the student entered college. This finding is not difficult to understand, as in China, most students usually live at home before college, and their behavior is heavily influenced by their parents. However, after entering university, students usually live on campus and their behavior is more likely to be influenced by classmates and friends. Anti-tobacco interventions for undergraduate students should therefore focus on changing the smoking behaviors and attitudes of students.

A student's awareness of tobacco hazards was not found to affect smoking initiation, but was found to affect their intention to quit smoking. In contrast, beliefs regarding smoking (e.g., the belief that smoking can relieve stress and improve social communication) were found to be significantly associated with a student's initiation of smoking rather than their intention to quit. This finding may be explained by the following. Students who have never smoked are usually curious about smoking, which could make them neglectful of the hazards associated with smoking. Students who have already started smoking are no longer curious about smoking and might be aware of the health risks involved, making them more likely to pay attention to and to accept the hazards of smoking, even though they may not admit it openly.

Higher SHSE among male students was found to increase the likelihood of them being a current smoker or initiating smoking after school enrollment. Therefore, creating a 
smoke-free environment is important to decreasing the smoking rate among these students. Ethnicity was found to be a strong predictor of smoking behavior among male medical students. The smoking rate among ethnic minority students, especially those of Tibetan ethnicity, was found to be much higher than that of Han students. Other researchers have also obtained similar conclusions among middle school students $(25,26)$. Taking the customs and local culture of Tibet into account, this phenomenon may be explained by the following reasons. First, Tibet is located in western China, where a lack of economic and educational development, and public health services might cause a series of problems which impact on students' smoking behaviors. Second, Tibet has a long tradition of alcohol drinking (27), and many studies have demonstrated the positive correlation between smoking and drinking (28). Therefore, the high smoking rate among Tibetan medical students may be closely associated with drinking habits. Third, there is a higher proportion of boarding schools in Tibet, and Tibetan children usually leave their parents to live in boarding schools when they are very young. Without parental discipline, Tibetan adolescents may be more likely to get into the habit of smoking and drinking.

\section{Limitations}

This study is one of the first to analyze the smoking behaviors (participation, initiation, and intention to quit) of male medical students in China, using a large sample covering 16 leading medical universities in China. However, this study is not free of flaws and may have the following limitations. First, the medical colleges covered in this study were not chosen randomly, and the study population only included second- and third-year male medical students. Therefore, care needs to be taken when generalizing the major findings from this study. However, given that the 16 colleges involved in this study were selected from different regions of China, and there was a similar number of top colleges and non-top colleges, this study can reveal reliable information about the current smoking status of Chinese male medical students.

\section{Conclusions}

The fact that the smoking prevalence among male medical students is lower than that of the non-medical male students in China suggests that medical students in China holds strong promise as a key group in the promotion of tobacco control in China.

The factors found by this study to influence a student's smoking participation included ethnicity and region, the student's anti-tobacco attitude, their parents' smoking behaviors, their best friend's attitude towards smoking, and individual-level SHSE, as well as whether the student believed that smoking could relieve stress. Factors affecting smoking initiation after school enrollment included whether a student was enrolled in a national top college, the student's anti-tobacco attitude, whether they believed smoking could relieve stress and improve social communication, their best friend's attitude towards smoking, and college-level and individual-level SHSE. Factors influencing intention to quit smoking included the student's awareness of tobaccoassociated risks, their anti-tobacco attitude, their best friend's attitude towards smoking, and whether they had been advised to quit smoking.

Some of these factors were found to influence all three type of smoking behavior measures (participation, initiation, and intention to quit); these factors included the student's anti-tobacco attitude and their best friend's attitude towards smoking. Some factors were only found to affect one or two measures of students' smoking behaviors; these included the smoking behaviors of the student's parents, the student's awareness of tobacco-associated risks, a student's belief that smoking could relieve stress or improve social communication, and college-level and individuallevel SHSE. Therefore, intervention measures should be developed by focusing on the particular smoking behavior that the school intends to target to ensure more effective implementation of the intervention.

\section{Acknowledgments}

The authors would like to express their sincere gratitude to the professor of Sichuan University, Juying Zhang, Xiao Ma, Huan Zhou, Ping Yuan, Peiyuan Qiu, and other teachers who supported for design, data collection and helped coordinate the implementation of the survey at involved institutions and all the students who participated in this survey.

Funding: None.

\section{Footnote}

Reporting Checklist: The authors have completed the SURGE reporting checklist. Available at http://dx.doi. org/10.21037/apm-20-2101 
Data Sharing Statement: Available at http://dx.doi. org/10.21037/apm-20-2101

Conflicts of Interest: All authors have completed the ICMJE uniform disclosure form (available at http://dx.doi. org/10.21037/apm-20-2101). The authors have no conflicts of interest to declare.

Ethical Statement: The authors are accountable for all aspects of the work in ensuring that questions related to the accuracy or integrity of any part of the work are appropriately investigated and resolved. All procedures performed in this study involving human participants were in accordance with the Declaration of Helsinki (as revised in 2013). The study was approved by institutional ethics committee of Sichuan University (No.: 20180412, the registration number of ethics committee) and informed consent was taken from all the participants.

Open Access Statement: This is an Open Access article distributed in accordance with the Creative Commons Attribution-NonCommercial-NoDerivs 4.0 International License (CC BY-NC-ND 4.0), which permits the noncommercial replication and distribution of the article with the strict proviso that no changes or edits are made and the original work is properly cited (including links to both the formal publication through the relevant DOI and the license). See: https://creativecommons.org/licenses/by-nc-nd/4.0/.

\section{References}

1. 2018 China Adults Tobacco Survey. Beijing: Chinese Center for Disease Control and Prevention, 2018.

2. Yang JJ, Yu D, Wen W, et al. Tobacco Smoking and Mortality in Asia: A Pooled Meta-analysis. JAMA Netw Open 2019;2:e191474.

3. Parascandola M, Xiao L. Tobacco and the lung cancer epidemic in China. Transl Lung Cancer Res 2019;8:S21-30.

4. Liu YN, Liu JM, Liu SW, et al. Death and impact of life expectancy attributable to smoking in China, 2013. Chinese Journal of Epidemiology 2017;38:1005.

5. Xu X, Zhang X, Hu TW, et al. Effects of global and domestic tobacco control policies on cigarette consumption per capita: an evaluation using monthly data in China. BMJ Open 2019;9:e025092.

6. WHO Report on the Global Tobacco Epidemic, 2017, Monitoring Tobacco Use and Prevention Policies. Geneva:
World Health Organization, 2017.

7. Goodchild M, Zheng R. Tobacco control and Healthy China 2030. Tob Control 2019;28:409-13.

8. Pärna K, Põld M, Ringmets I. Trends in smoking behaviour among Estonian physicians in 1982-2014. Bmc Public Health 2017;18:55.

9. Dülger S, Doğan C, Dikiş ÖŞ, et al. Analysis of the Role of Physicians in the Cessation of Cigarette Smoking Based on Medical Specialization. Clinics (Sao Paulo) 2018;73:e347.

10. Jankowski M, Kaleta D, Zgliczyński WS, et al. Cigarette and E-Cigarette Use and Smoking Cessation Practices among Physicians in Poland. Int J Environ Res Public Health 2019;16:3595.

11. Nilan K, McKeever TM, McNeill A, et al. Prevalence of tobacco use in healthcare workers: A systematic review and meta-analysis. PLoS One 2019;14:e0220168.

12. Meijer E, Van der Kleij RMJJ, Chavannes NH. Facilitating smoking cessation in patients who smoke: a largescale cross-sectional comparison of fourteen groups of healthcare providers. BMC Health Serv Res 2019;19:750.

13. Codern-Bové N. Smoking cessation assisted by primary healthcare professionals. J Nursing Education Practice 2016;6:59-68.

14. Aluckal E, Kunnilathu A. Role of dental professionals in tobacco control. International Journal of Clinical Dental Sciences 2016;7:1-4.

15. Xu Y, Wang RF, Ma X. Associations of smoking behavior with health beliefs and time perspective among college students in Chengdu. Chinese Journal of School Health 2017;38:666-9.

16. Zhu ZY, Zheng PP. Current smoking prevalence and influencing factors among university students in Shanghai. Journal of Shanghai Jiaotong University (Medical Science) 2017;37:155-60.

17. Li FJ, Sun J, He J, et al. Cross-sectional investigation on smoking behavior among college students in Henan. Chinese Primary Health Care 2017;31:14-5.

18. Niu L, Liu Y, Luo D, et al. Current Smoking Behavior Among Medical Students in Mainland China: A Systematic Review and Meta-Analysis. Asia Pac J Public Health 2018;30:610-23.

19. Peng S, Yu L, Yang T, et al. Susceptibility to smoking and determinants among medical students: A representative nationwide study in China. Tob Induc Dis 2019;17:36.

20. Wu Y, Fan H, Guo Z, et al. Factors Associated With Smoking Intentions Among Chinese College Students. Am J Mens Health 2019;13:1557988318818285.

21. Xu Y, Yang Y, Ma X. Time perspective, optimistic bias, and 
self-control among different statuses of university smokers in China: a cross-sectional study. Psychol Health Med 2018;23:1054-9.

22. Yang GL, Hu L, Zhang XH, et al. An investigation on the situation on smoking tries and its influencing factors among college students in Wenzhou. Zhejiang Journal of Preventive Medicine 2016;28:458-60, 464.

23. Xu Y, Xu SY, Wu QQ, et al. Study on the epidemiological status of tobacco use among teenagers in Zhejiang province, China. Zhonghua Liu Xing Bing Xue Za Zhi 2016;37:164-8.

24. Duan JL, Lyu RY, Zhao H, et al. Analysis on the variation of tobacco use behavior among college students and middle school students from 2008 to 2014 in Beijing. Chinese Journal of School Health 2016;37:968-72.

25. Nima QC, Song QF, Suolang DJ, et al. The prevalence

Cite this article as: Yang X, Chen W, Peng X, Wei C, Xin J, Tang J, Chen J, Zeng Z, Luan R. The prevalence of smoking in male medical students from 16 Chinese medical colleges and the associated factors. Ann Palliat Med 2020;9(6):4054-4065. doi: 10.21037/apm-20-2101 and influencing factors of smoking behavior among junior middle school students in Tibet Autonomous Region. Chinese Journal of Health Education 2016;32:396-9, 403.

26. Xu X, Liu D, Sharma M, et al. Prevalence and Determinants of Current Smoking and Intention to Smoke among Secondary School Students: A Cross-Sectional Survey among Han and Tujia Nationalities in China. Int J Environ Res Public Health 2017;14:1323.

27. Kangzhuo B, Chunhua, Yangla, et al. Alcohol drinking behavior among native adult Tibetans in Lhasa. Chinese Journal of Public Health 2016;32:609-12.

28. Cao W, Yang TT, Li L, et al. Drinking among adolescents aged 15-17 years in China during 2010-2012. Chinese Journal of School Health 2017;38:1296-8, 1302.

(English Language Editors: L. Gray and J. Reynolds) 